\title{
LA ÚLTIMA VOLUNTAD DEL DIPUTADO QUITEÑO JOSÉ MEXÍA DE LEQUERICA ${ }^{1}$
}

\author{
Gloria de los Ángeles ZARZA RONDÓN \\ Universidad de Cádiz
}

\begin{abstract}
RESUMEN: El artículo que presentamos pretende aclarar distintos datos historiográficos sobre la vida del diputado a Cortes por el Nuevo Reino de Granada, José Mexía de Lequerica. A través de la documentación consultada en los Archivos Históricos, Municipal y Provincial de Cádiz, además del Archivo Parroquial de San Antonio, hemos descubierto cuál fue su verdadera ubicación urbanística, con quiénes compartió el final de su vida, cuáles fueron sus últimas voluntades antes de fallecer, y cómo éstas se llevaron a cabo por sus albaceas testamentarios, ofreciendo así un panorama completo, y hasta ahora desconocido, sobre los últimos años de uno de los diputados hispanoamericanos más trascendentales del Cádiz doceañista.
\end{abstract}

PALABRAS CLAVE: Protocolo notarial, Nuevo Reino de Granada, acta de defunción, padrón, Cortes de Cádiz.

ABSTRACT: The article that we sense beforehand tries to clarify different information historiográficos on the life of the deputy to Spanish Parliament for the New Kingdom of Granada, Jose Mexía de Lequerica. Across the documentation consulted in the Historical, Municipal and Provincial Files of Cadiz, besides the Parochial File of San Antonio, we have discovered which was his real urban development location, with whom he shared the end of his life, which were his last wills before expiring, and how these were carried out by his testamentary executors, offering this way a complete panorama, and till now unknown, on the last years of one of the most transcendental Spanish-American deputies of the Cadiz doceañista.

KEYWORDS: Notarial protocol, New Kingdom of Granada, death certificate, poll, Spanish Parliament of Cadiz.

\section{FUENTES DOCUMENTALES DE LA ESTANCIA Y FALLECIMIENTO DE JOSÉ MEXÍA LEQUERICA EN CÁDIZ.}

El artículo que presentamos forma parte de una investigación más amplia que

${ }^{1}$ Recibido el 30 de junio de 2011. Aceptado en el Consejo de 8 de noviembre de 2011. 
constituye mi tesis doctoral ${ }^{2}$. La fuente principal que hemos utilizado ha sido el protocolo notarial ${ }^{3}$, en especial, las disposiciones testamentarias y los poderes notariales del Archivo Histórico Provincial de Cádiz, aportándonos una información minuciosa y extraordinaria en torno a la cual hemos podido investigar las bases socio-económicas de la burguesía de negocios de la carrera de Indias, las estructuras familiares, las redes sociales y de poder, la vida cotidiana y las actitudes mentales $^{4}$ de los referidos actores sociales.

Esta documentación ha sido completada con la información procedente de los padrones del Archivo Histórico Municipal gaditano, que nos aportan valores cuantitativos y cualitativos sobre la población americana asentada en la ciudad en este período.

Una vez finalizado el acopio documental de sendos archivos, para la elaboración de este artículo, hemos seleccionado toda la información referida al diputado quiteño, basando nuestra investigación en el análisis de dos documentos procedentes del Archivo Histórico Provincial: el primero, un poder para testar que otorgó el diputado dos días antes de fallecer, el 25 de octubre de $1813^{5}$; y el segundo, el testamento póstumo ${ }^{6}$ datado el mes de noviembre del mismo año, otorgado por su primer albacea, José de Peñaranda, el cual se tomó la licencia de reformar alguna de las últimas voluntades de Lequerica. También hemos seguido la pista de José Mexía en los padrones relativos a los años constitucionales ${ }^{7}$ que obran

${ }^{2}$ G. ZARZa Rondón.: Cádiz, Puerto y Puerta de América: presencia de hispanoamericanos en la ciudad entre 1740 y 1840. (En prensa).

${ }^{3}$ Sobre las posibilidades que ofrecen los Protocolos véanse las Actas del II Coloquio de Metodología Histórica Aplicada (1984), La documentación Notarial y la Historia. Santiago de Compostela, Vol. II. Del mismo modo, también hemos de tener en cuenta el artículo de A. EIRAS RoEl (1980): «La documentación de Protocolos Notariales en la reciente historiografía modernista», en Estudis Historics i Documents dels Arxius de Portocols, Barcelona, $\mathrm{n}^{\circ}$ VIII pp. 7- 77

${ }^{4}$ Nos ha resultado de mucha utilidad el trabajo de M ${ }^{a}$ J. DE LA PASCUA (1990): Vivir la muerte en el Cádiz del setecientos, Cádiz. Fundación Municipal de Cultura. La autora hace uso de los testamentos como fuente principal sobre la cual analiza las actitudes individuales y colectivas ante la muerte.

5 Archivo Histórico Provincial de Cádiz. En adelante AHPC. Sección de Protocolos Notariales. Poder para testar de José Mexía. Libro 1493. Año de 1813. pp. 92- 98.

6 AHPC. Sección Protocolos Notariales. Testamento de 17 de Noviembre de 1813. Libro 1493, pp. 156- 169.

${ }^{7}$ Archivo Histórico Municipal de Cádiz, en adelante AHMC: Año de 1810. Sección de Padrones. $\mathrm{N}^{\circ}$ de orden L. (Libro) 9401 y L. 9476; Año de 1811, No de orden L.1044 al L. 1054 (10 tomos); Año de 1812. $\mathrm{N}^{\circ}$ de orden L.1031 al L. 1043 (13 tomos); y Año de 1813, $\mathrm{N}^{\circ}$ de orden L. 1055 al L. 1060 (6 tomos) 
en el Archivo Histórico Municipal, comprobando en qué barrio, calle y número exactos residió el diputado los últimos años de su vida, con quiénes compartió la vivienda, y quiénes eran sus vecinos. Por último, hemos hallado el extracto de su acta de defunción en el Archivo parroquial de la iglesia de San Antonio, no pudiendo acceder al documento literal, ya que éste se hallaba archivado en los fondos del cementerio gaditano, San José Extramuros ${ }^{8}$, lugar en donde fue enterrado José Mexía de Lequerica, y cuyos archivos fueron destruidos en su totalidad durante la guerra civil española (1936-1939), por lo que en el referido cementerio sólo existen partidas de defunción posteriores a 1939.

En relación a las fuentes documentales testamentarias ${ }^{9}$, creemos conveniente señalar que su uso se extendió durante el Antiguo Régimen a todas las clases sociales, en una sociedad marcadamente sacralizada y jerarquizada que se preocupó de prolongar su status aún después de la muerte, y siendo el sentimiento de proximidad a ella la razón que les impulsaba a testar. ${ }^{10}$

${ }^{8}$ Ma J. DE LA PASCUa (1990): Vivir la muerte en el Cádiz del setecientos. Cádiz. Fundación Municipal de Cultura. p. 153: Recordemos la Real Cédula de 3 de Abril de 1787, donde se prohibían a partir de entonces los enterramientos intramuros. No obstante, hemos de destacar, que en Cádiz, dichas prohibiciones habían caído en saco roto, bien por la inercia del propio Ayuntamiento, bien por la falta de interés del cabildo eclesiástico o por la misma oposición de los fieles. A partir de 1800, cuando comience a extenderse en Cádiz la epidemia de fiebre amarilla, comenzarían a cumplirse sin demora, ante la urgencia de la situación, las órdenes de la Real Cédula. Fue destinado como cementerio común el de la Parroquia de San José, extramuros de la ciudad, al que, dada su pequeñez, hubo que añadir un pedazo de terreno continuo.

9 M Paz DEL CERRO BOHÓRQuez (2005): Mujer, herencia y patrimonio en la sociedad rural gaditana del Antiguo Régimen. Alcalá de los Gazules, Chiclana de la Frontera y Medina Sidonia. (1670-1750). Cádiz. Servicio de Publicaciones de la Universidad de Cádiz. Dicha obra está siendo utilizada como fuente bibliográfica en nuestras investigaciones, y en ella se hace hincapié en la importancia que revisten los testamentos como herramienta idónea que nos aproxima al estudio de las actitudes colectivas y a la historia de las mentalidades. A través de los mismos nos acercamos a la vida cotidiana, a los niveles socioeconómicos de los otorgantes, siendo fundamental para el estudio de la historia social y de las mentalidades.

${ }^{10}$ A lo largo de nuestra investigación hemos constatado, que hay diversas razones para otorgar un testamento: la coyuntura de un viaje próximo, una enfermedad inesperada y, por último, la ancianidad. Aparte del caso de José Mexía, contamos con los testamentos otorgados por diputados como Octaviano Obregón, representante por Guanajuato, Esteban Palacio, suplente por Venezuela, o José Manuel Couto, diputado por Nueva España entre otros. De los diputados analizados, predominan la segunda y la tercera; es decir, la enfermedad prematura como en el caso de Lequerica o la ancianidad como ocurre a Fermín de Clemente. (Nota de la autora). También corrobora esta aseveración la obra de J. PANIAgua PÉREZ (1990): Morir en Cádiz (1650-1859). La vida y la muerte de las gentes de los obispados de Astorga y León en Cádiz, así como de Oviedo en la provincia de León. León. Editorial Lobo Sapiens. 
Cabe destacar, que la estructura de los documentos analizados responde a las características generales de este tipo de fuentes escritas: una primera parte espiritual o religiosa; y una segunda referida a cuestiones materiales. Será esta segunda parte del documento la que nos resulta más interesante y sustancial, ya que en ella el testador detalla extensamente todo lo relativo a aspectos personales. En el caso de Mexía de Lequerica, es donde hallamos toda la información relativa a su vida en nuestra ciudad, quiénes fueron los beneficiarios de su exiguo patrimonio, a saber: Esteban Palacio, representante por Venezuela y tío materno de Simón Bolívar; y también el nombramiento de su heredera universal, dato sorprendente y revelador que veremos más adelante.

Respecto al lugar en el que vivió el diputado dentro del espacio urbano de la ciudad gaditana, hasta el momento, contábamos con diferentes datos procedentes de fuentes muy conocidas ${ }^{11}$, que localizaban la vivienda de Lequerica en el barrio del Pilar, concretamente en la calle Ahumada número 18. Del mismo modo, en la consulta del acta de defunción ${ }^{12}$, encontramos domiciliado al diputado en la Plaza de San Antonio, sin especificar el número, aunque en la actualidad se encuentra en el lugar una placa conmemorativa ${ }^{13}$. Así nos hallamos ante dos residencias distintas para una misma persona no coincidentes en la ciudad de Cádiz, lo cual nos llevó a la investigación exhaustiva de los padrones del Archivo Histórico Municipal

${ }^{11}$ Nos referimos a la obra de R. Solís (2000): El Cádiz de las Cortes. La vida en la ciudad en los años de 1810 a 1313. Madrid. Sílex Ediciones. p. 270. El autor sitúa el domicilio de José Mexía en la calle Ahumada 18. Con anterioridad, en la página 268, cita que Mexía Lequerica se hospeda en casa de la familia San Juan, de la cual no hemos hallado noticia en las investigaciones realizadas para la elaboración de este artículo. De hecho, Solís no da fuente alguna a la que recurrió para la afirmación de dicho dato.

12 Archivo Parroquial de la Iglesia de San Antonio de Cádiz. Libro de defunciones No 4, folio 47, $\mathrm{n}^{\circ}$ 461. El extracto dice lo siguiente: En la ciudad de Cádiz veinte y siete de octubre de mil ochocientos y trece años murió el Sr. Dn. Joséf Mexía y Lequerica, feligres de esta parroquia de San Antonio. Diputado en Cortes por la provincia de Santa fee y Oficial de la Secretaría de Gracia y Justicia, natural de Quito el Nuevo Reyno de Granada en el Perú, de edad de 34 años, de estado soltero, hijo de Dn. Joséf Mexía y $D^{a}$ Joaquina Lequerica. Recivio el Santo Oleo. Testo ante Dn. Antonio Govirand y Martinez Escrivano Publico y del numero de esta ciudad. Se enterro en el Cementerio General Extramuros de esta dicha ciudad. Sin funeral. Vivía en la Plaza de San Antonio. Y lo firmo como cura proprio. Juan Bautista Carrera.

${ }^{13}$ En la actualidad, en el número 13 de la Plaza de San Antonio hay una placa conmemorativainstitucional de 1912, año del Centenario, en la que se alude a la labor de José Mexía de Lequerica como diputado a Cortes, lo que ha generado el error de creer que en esta casa fue donde falleció, ya que sus exequias se llevaron a cabo en la Parroquia de San Antonio, muy próxima a dicha vivienda. La casa en la que murió el diputado, en la calle de San José, pertenecía a dicha jurisdicción eclesiástica, distando de la misma unos 500 metros, por lo cual, el extracto de su acta de defunción se alberga en el archivo del citado templo. 
confeccionados entre 1810 y 1813. Tras la consulta del Padrón de $1813^{14}$, constatamos que el diputado no vivía en la calle Ahumada, verificamos que en dicha calle y número habitaban dos familias que poco o nada tenían que ver con José Mexía y de las que dejamos constancia en la nota a pie de página que sigue. ${ }^{15}$ Igual sucedía con las personas empadronadas en estos momentos en la Plaza de San Antonio y de las que señalamos su presencia documentalmente ${ }^{16}$. Ni rastro del

${ }^{14}$ AHMC: Sección Padrones. No de orden L. 1055- L. 1060 (6 tomos)

15 AHMC: Sección Padrones. N $N^{\circ}$ de orden L. 1055. Barrio del Pilar, calle Ahumada 18. Comprobamos que en dicha vivienda habitaban dos de los hermanos de la familia Lobo, Rafael y Francisco de Paula, de larga tradición comercial y mercantil en Cádiz. Su padre, Juan Jácome Lobo y Candiani, más conocido como Juan Santiago, nacido en Cádiz el 8 de febrero de 1722, para 1751 ya se dedicaba activamente al comercio en esta ciudad, y aparece inscrito en los libros de matrícula del consulado. Contrajo matrimonio con Manuela Francisca Javiera García de Campos y Arraido, natural de la ciudad de Veracruz. El padre de estos dos hermanos se mantuvo vinculado al comercio de Jalapa, de donde es natural Francisco de Paula, hasta 1775, cuando se traslada con su familia a Cádiz, domiciliándose en Puerto Real, lugar en que desempeñó el puesto de Diputado del Concejo, además de seguir vinculado al comercio de la Carrera de Indias. Op. cit. en J. SANCHIZ, Y J. I. CONDE DíaZ RuBín.: «La familia Monterde y Antillón en Nueva España. Reconstrución genealógica». En Estudios de historia novohispana. pp. 93- 164.. Efectivamente, encontramos al padre de los moradores de la calle Ahumada matriculado en la Carrera de Indias a partir de 1751, en J. RuIz RIVERA (1988): El Consulado de Cádiz. Matrículas de comerciantes. 1730- 1823.San Fernando. Diputación Provincial de Cádiz. p. 176. El primero de los hermanos que aparece en el padrón de 1813, es Rafael Lobo, natural de Cádiz, de 36 años, Capitán de navío de la Armada Nacional, casado con Juana Pico, gaditana de 28 años, y padres de dos hijas, Blanca de 11 años, y María Joaquina de 3. En cuanto al segundo hermano, Francisco de Paula, el padrón nos informa que era originario de Jalapa, en el Virreinato de Nueva España, de 42 años, soltero y presbítero. Acompañan a la familia Lobo, otra familia vinculada, no al comercio, sino a la élite política de la época, los Mendizábal. El padrón nos refiere la presencia de Blas de Mendizábal, Caballero de la Orden de Carlos III por Decreto de 2 de enero de 1816, y cónsul español en Rusia durante el Gobierno de Carlos IV, en J. A. ARMiLlas, L. SuÁREZ FernándeZ, y C. CORONA BARATECH (1984).: Historia General de España y América: La España de las reformas hasta el final del reinado de Carlos IV. Madrid. Ediciones Rialp S. A. p. 320. Junto a Blas de Mendizábal, aparece su esposa Hermenegilda Mendizábal, ambos naturales de Bilbao, el primero de 42 años, de la mujer el padrón no refiere edad alguna. Finalmente, en la casa se hallan domiciliados cuatro sirvientes, un hombre, Antonio Rostales, soltero, oriundo de Italia, y tres mujeres solteras: Isabel Beltrán, de Moguer, con 53 años; Juana Marín, de San Lúcar, de 40, y Guadalupe Landero, de la ciudad de Veracruz, de 38 años.

16 AHMC: Padrón de 1813. Sección Padrones. $\mathrm{N}^{\mathrm{o}}$ de orden L.1056. Hemos consultado los vecinos que habitaban en la Plaza de la Constitución (actual Plaza de San Antonio), y no hallamos relación alguna con el diputado. Los domiciliados en dicha plaza eran:

- Casa número 1, como cabeza de familia, la viuda gaditana Catalina Josefa Prat, dedicada al comercio, posiblemente el oficio de su difunto esposo. Junto a ella, sus cuatro hijos nacidos en Cádiz, $\mathrm{y}$ un sirviente gallego.

- Casa número 2, Manuel Martínez de Pinillos, natural de Perú, Alférez Mayor de navío, junto a Jacinto Velasco, también peruano, ex jesuita, y sus correspondientes criados. 
- Casa número 3, José Martínez de Vengoa, gaditano, Sargento Mayor, sus hermanos Félix de Vengoa, Capitán de Infantería, y José María, Cadete. Junto a ellos el subteniente de la Isla de León, Juan Beltrán. Les acompañan sus respectivos sirvientes.

- Casa número 4, el comerciante natural de Vigo, Pedro Navas de Vera, su mujer Catalina Pérez, sus tres hijos y el matrimonio formado por Vicente de Barbas, Teniente Coronel, y su esposa Tomasa Corbero, junto a sus dos hijos y los sirvientes de la vivienda.

- Casa número 5, no aparece en el padrón, posiblemente porque se encuentrara vacía.

- Casa número6, el Coronel Comandante gaditano Agustín Serno, casado con Gertrudis Retortilla, sus tres hijos y un sirviente gallego, junto al matrimonio formado por el comerciante de seda santanderino José de la Cuesta, su esposa, la gaditana Rosa Tomás, y sus tres hijos. Les acompaña el dependiente de la tienda de seda del anterior inquilino, Joaquín de Brenna, también de Santander.

- Casa número 7, Cayetano Leiva, boticario vizcaino, y el zapatero gaditano Felipe Negrís.

- Casa número 8, Pedro de Fuentes, Presbítero de Cádiz; el comerciante alemán Juan Bavven, y la viuda Josefa de Fuentes, junto a sus tres hermanos, Liberato, Filomena y Candelaria.

- Casa número 9, no aparece en el padrón como domicilio habitado.

- Casa número 10, el comerciante Gregorio Santa Cruz, de Cartagena de Levante, junto a su esposa, la gaditana Isabel de Blaca, y sus siete hijos. Con ellos convivían el administrador de lotería Tomás Villarreal, burgalés, y su hermano Iñigo Villareal, dependiente de la administración de loteria.

- Casa número 11, Cristóbal Artecona, gaditano dedicado a las rentas, y su esposa Rosa de Sandobal, de Jerez.

- Casa número 12, el comerciante gaditano José de Godeyne, su hijo José María Godeyne, Oficial de Infantería, junto a su esposa María Rosario Terry, con ellos los sirvientes de la casa.

- Casa número 13, habitada por el comerciante castellano Sebastián Torres, casado con la gaditana Antonia Godeyne, sus seis hijos y los respectivos criados.

- Casa número 14, el subteniente Capitán, Claudio Orellano, natural de Algeciras, su esposa María Josefa Romero, de Cádiz, Nicolás de Toro, de Aguilar de la Frontera, Teniente de navío, junto a su esposa, Josefa Espejo y sus cuatro hijos. Junto a ellos el comerciante de Rota, Jorge Lynch, con su esposa Lucía Rodríguez y una hija.

- Casa número 15, el comerciante santanderino Manuel Gómez de los Ríos, casado con la gaditana María Teresa Morillo, sus cuatro hijos y los criados del hogar.

- Casa número 16, Rita Valenciano, gaditana dedicada a sus rentas, Antonio de Lenny, sevillano y administrados de loterías, Benito Pachi, romano, dependiente de la administración de lotería, y Pedro de Hoyos Bustamente, cafetero de Castilla La Vieja.

- Casa número 17, Tomás Istúriz, comerciante gaditano, junto a sus hermanos Francisco Javier e Ignacio Istúriz, también dedicados al comercio. Vive con ellos el maestro zapatero Manuel Arcolea, sevillano, y los criados de la casa.

- Casa número 18, Vicente Cano, de Cádiz, propietario y dedicado a la administración de sus rentas, viudo; Agustín de la Loncha, dependiente de una casa de comercio, y los respectivos sirvientes de la vivienda.

- Casa número 19, Agustín Salaverria, del cual no se indica su profesión, pero estaría posiblemente dedicado al comercio, o a la administración de propiedades en la ciudad. El piloto Francisco Paradillo, natural de Castrovidales, con su esposa Josefa Bonnely, gaditana, y sus cinco hijos. Joaquín Gómez de la Rueda, Francisco Ibáñez y Fernando de la Huerta, que regentaban una taberna, y del resto de habitantes de la casa, todas mujeres no se informa sobre su oficio, de lo que deducimos que serían criadas del hogar. 
diputado en ninguno de los dos domicilios donde supuestamente falleció Lequerica.

Tras verificar que los diferentes datos sobre los domicilios asignados a Mexía de Lequerica eran incorrectos, continuamos con su búsqueda y basándonos en la consulta de las fuentes documentales primarias, pudimos localizar la vivienda del diputado en el Padrón de $1813^{17}$ en el barrio de San Antonio, pero no en la Plaza del mismo nombre, sino en la calle San José número 60.

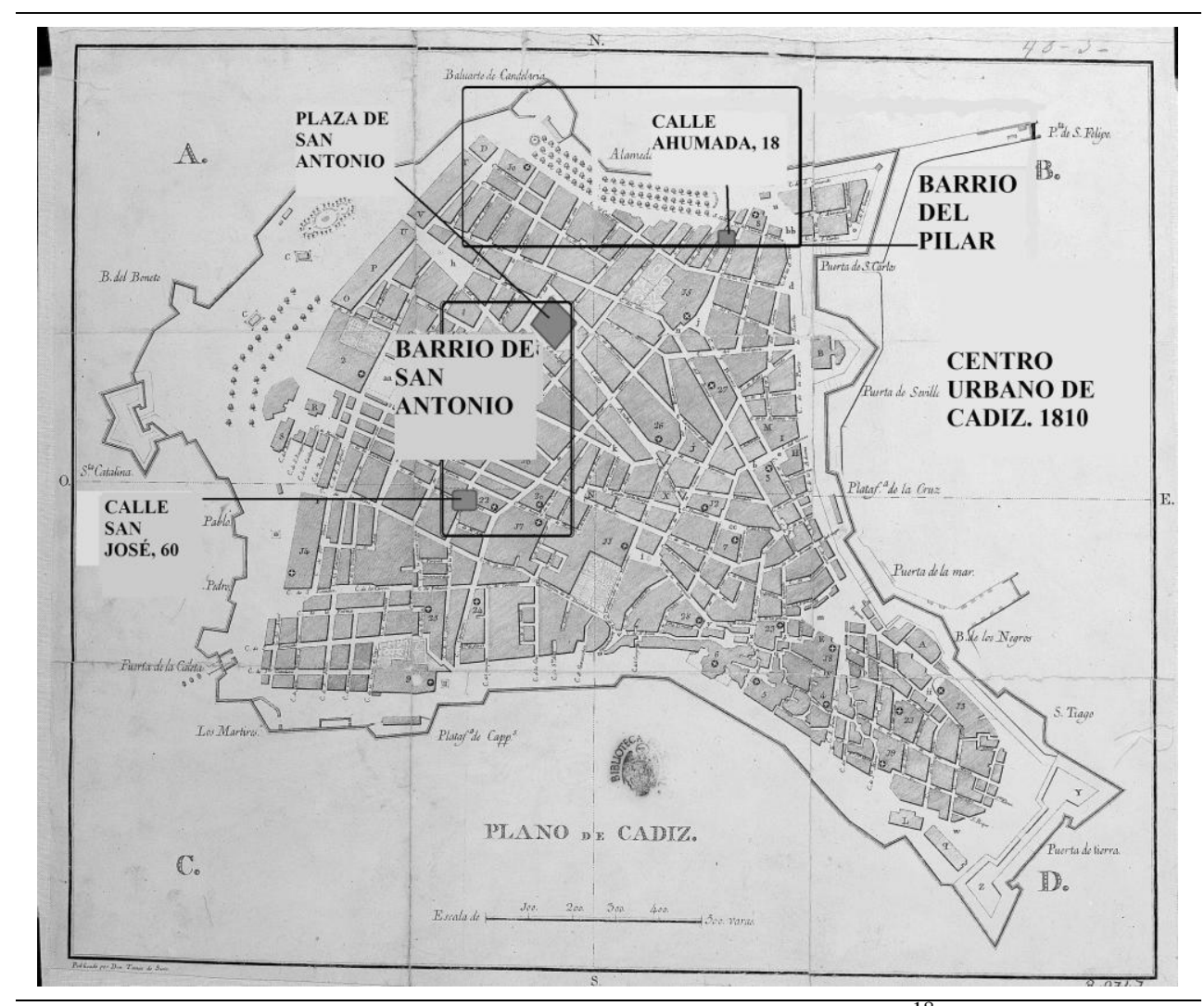

Elaboración propia a partir del Plano de la ciudad de Cádiz de $1810 .^{18}$

17 AHMC: Padrón de 1813Sección Padrones. Nº de Orden L. 1.056.

18 http://bdh.bne.es/bnesearch/detalle/91165: Cádiz. Planos de Población 18. [Material Cartográfico] Mapa de la ciudad de Cádiz para el año 1810, realizado por Tomás de Sisto. Actualmente se encuentra en los fondos de la Biblioteca Nacional, Madrid. [Consultado 19- 10 2011]. En el plano podemos ver situados los domicilios erróneos que le fueron adjudicados a Lequerica; el 
Junto a Lequerica, natural de la ciudad de Quito, de 36 años, y soltero, según consta en el Padrón, se encuentran registradas diferentes personas relacionadas con el diputado:

$\checkmark$ - Antonio Carcerea, escribiente, posiblemente empleado de Lequerica;

$\checkmark$ - José Guzmán, secretario de guerra, originario de Madrid, con su esposa, María Samaniego; su hermana, María Guzmán; y un niño de 8 años, Manuel de Montalvo, del que nada se especifica sobre la relación de parentesco con los habitantes de la casa, por lo que deducimos que probablemente sería un sobrino, allegado, criado o hijo natural de la familia Guzmán- Samaniego.

$\checkmark$ - Gertrudis Benito, natural de Belmonte, provincia de Cuenca, de 24 años, esposa del peruano Joaquín Caldeiro, de 34. Será precisamente Gertrudis, la designada por el diputado como su universal heredera.

Conociendo de antemano quiénes habían sido los dos albaceas de Lequerica, hallamos en el citado Padrón de 1813, el domicilio de uno de los dos individuos, Juan Manuel Aréjula, ubicado en la mencionada callé San José, número $55^{19}$. No queremos dejar pasar la ocasión, sin señalar que este segundo albacea de Lequerica, fue vicedirector del Colegio de Cirugía de Cádiz, y uno de los médicos encargados de combatir la epidemia de fiebre amarilla de la que sucumbió nuestro protagonista.

primero de ellos en la calle Ahumada 18. Se situaba dentro del llamado barrio del Pilar, pertenecía en su mayor parte a la parroquia de San Antonio, y se constituía como uno de los barrios más lujosos de la ciudad, con buenas casas y habitado por las altas esferas del comercio de la ciudad. En: R. Solís (2000): El Cádiz de las Cortes. La vida en la ciudad en los años de 1810 a 1313. Madrid. Sílex Ediciones. p. 268- 270. En cuanto al barrio de San Antonio, que tras el período constitucional pasaría a denominarse barrio de la Constitución, está centrado entre la plaza de San Antonio o de la Constitución y el paseo de la Alameda, paseo favorito de los gaditanos. La plaza de San Antonio o Constitución era el centro de la vida pública a nivel local. Continuación de la calle Ancha, se convirtió en lugar de paseo y tertulia en los atardeceres. En la plaza tenían lugar cafés y hoteles importantes. El barrio contaba en su interior con dos zonas bien diferenciadas: entre la calle Ancha y la Alameda, era una zona residencial, donde tenían su alojamiento gentes de dinero, y donde vivían las familias más pudientes de la ciudad. Por ello el barrio aporta importantes números en los sectores comerciales, de profesiones liberales, propietarios, sirvientes, así como de empleados públicos. Respecto a la otra zona del barrio de San Antonio, está situada en el sector Oeste, junto al mar abierto, cerrado por cuarteles y zonas militares, es lugar de residencias populares, y de profesiones con menor nivel económico. En: A. Ramos Santana (1992): Historia de Cádiz. Cádiz en el siglo XIX. De ciudad soberana a capital de provincia. Vol. III.Madrid. Ediciones Sílex. pp. 58- 60.

${ }^{19}$ AHMC. Sección Padrones. Padrón de 1813. Libro no de orden 1056 


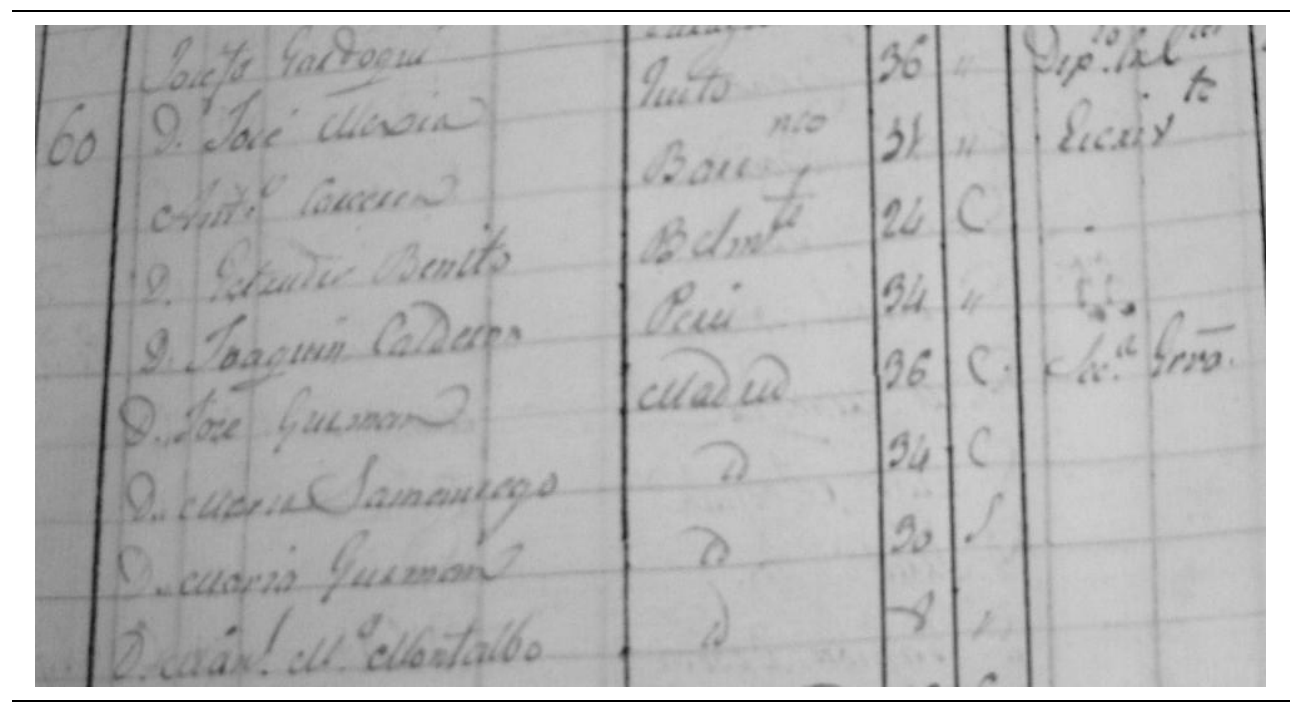

Extracto de la página en la que aparece domiciliado el diputado por Quito José Mexía Lequerica. Archivo Histórico Municipal de Cádiz ${ }^{20}$

De este modo evidenciamos cuál fue el domicilio real de José Mexía Lequerica según consta en las fuentes documentales. No obstante, nos asalta la duda relativa al dato que ofrece el extracto de su acta de defunción, donde se especifica que vivía en la Plaza de San Antonio justo antes de su fallecimiento. Incluso, como prueba de ello, encontramos en la citada plaza una placa institucional sobre la labor del diputado en las Cortes doceañistas. En cualquier caso, y siempre remitiéndonos a la documentación consultada, queda comprobado que el domicilio del diputado estuvo situado en la citada calle San José número 60. Podemos conjeturar especulando con la idea de que pocos días antes de fallecer, por motivos que desconocemos, Lequerica se trasladara a la vivienda de la Plaza de San Antonio, pero no contamos con ninguna prueba fidedigna que nos de fe de ello, ni vínculo alguno con las familias que vivían en dicha plaza, y de las que ya hemos reseñado sus características ${ }^{21}$.

\section{PRESENCIA Y MUERTE DE JOSÉ MEXIA LEQUERICA EN CÁDIZ.}

Analizaremos en este segundo apartado cómo a través de los dos documentos hallado en el Archivo Histórico Provincial de Cádiz, (el poder otorgado por el

\footnotetext{
${ }^{20}$ Foto realizada por la autora. AHMC: Sección Padrones. Padrón de 1813. Libro $\mathrm{n}^{\mathbf{o}}$ de orden 1056.

${ }^{21}$ Consultar nota a pie de página número 15.
} 
diputado, y el posterior testamento conferido por su primer albacea), José Mexía, nos muestra una imagen de su propia vida y de su muerte: su lugar de origen, edad y estado civil, siendo éste uno de los datos más cuestionados; su situación económica, el papel social que jugó, los lazos familiares, profesionales, de amistad...., todo ello, espejos que reflejan la visión que el diputado tenía de lo que hasta entonces había sido su trayectoria vital, y cómo se acercaba el final de ésta.

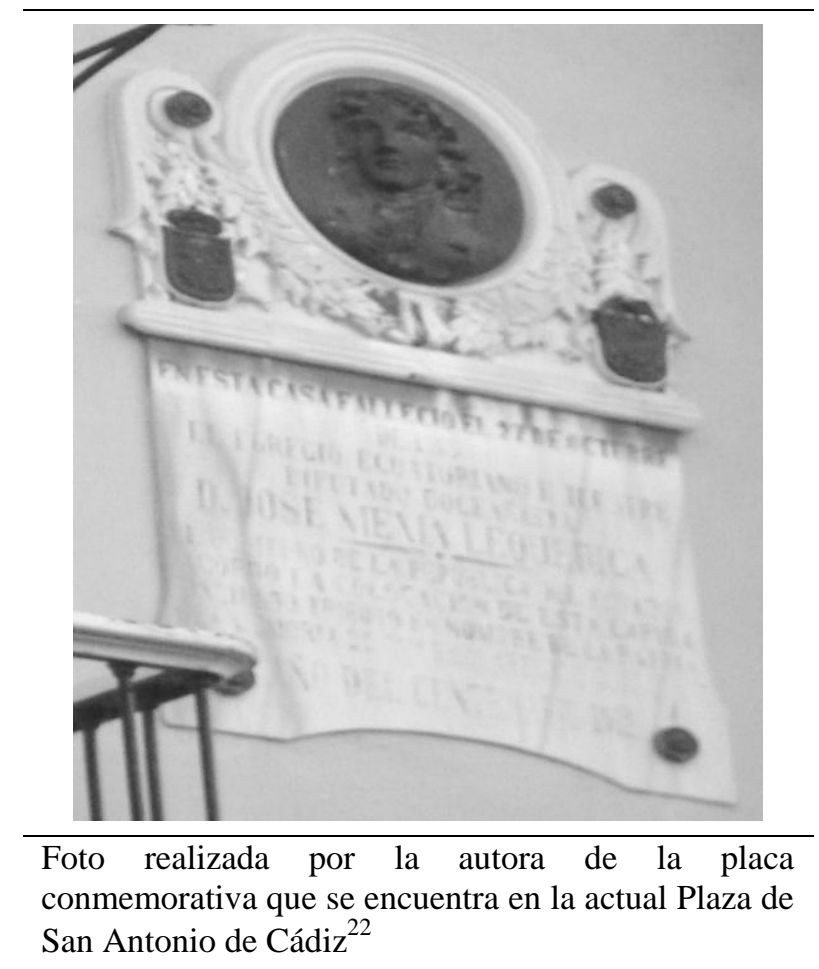

Sin más preámbulo, pasemos en primer lugar a conocer de forma general cómo transcurrió la vida del diputado hasta el momento de su llegada a la ciudad de Cádiz.

${ }^{22}$ En dicha placa puede leerse esta leyenda:

En esta casa falleció el 27 de octubre de 1813 El egregio ecuatoriano e ilustre diputado doceañista D. José Mexía Lequerica

El gobierno de la República del Ecuador Acordó la colocación de esta lápida rindiendo Tributo en nombre de la patria a la memoria De tan esclarecido ciudadano. Año del Centerario. 1912. 
José Mexía Lequerica nació en Quito el 24 de mayo de 1777, en la casa que su madre poseía en la calle Guayaquil frente a la actual capilla del colegio de los Sagrados Corazones, en la parroquia del Sagrario ${ }^{23}$. Hijo del abogado José Mexía del Valle y Moreto y Manuela Lequerica Barrioteca. Sus biógrafos destacan el hecho de que fuera engendrado en una relación ilegítima entre Manuela Lequerica, casada con Antonio Cerrajería, y José Mejía del Valle, soltero, abogado de la Real Audiencia y posteriormente Gobernador, Auditor de Guerra y Asesor del Gobierno en Guayaquil, condicionó parte de la carrera profesional de Mejía. ${ }^{24}$

Cuando tenía diez años ingresó en el colegio de San Fernando. Allí tuvo como maestro a José Joaquín Olmedo, de quien recibió una educación laica. Más tarde coincidirá con su antiguo maestro de primeras letras en las Cortes gaditanas al ser elegido Olmedo diputado por Guayaquil. ${ }^{25}$

José Mexía de Lequerica creció probablemente con su madre, quien no escatimó sacrificio y lo orientó al aprendizaje de la Gramática Latina durante tres años con Fray Ignacio González, en el colegio de dominicos de San Fernando. Prosiguió con estudios de filosofía, álgebra, geometría y trigonometría. En el referido colegio de los dominicos conoce a su principal mentor, Eugenio Espejo, quien empezó a dirigir su formación moldeando su carácter y aconsejándolo dentro de los nuevos cánones de la Ilustración. La muerte de Espejo fue un duro golpe para Lequerica, quien acabó contrayendo matrimonio el 29 de junio de 1796, con la hermana de su mentor, Manuela Espejo, ella de 44 años de edad, y él con apenas 21. Manuela, era algo desengañada físicamente, de maneras suaves, pero de templado y recio carácter, algo instruida y conocedora de la medicina y la miseria ${ }^{26}$, era además propietaria de la riquísima biblioteca de su hermano. Como puede comprobarse, fue un matrimonio de conveniencia que escandalizó al vecindario. ${ }^{27}$

En 1806 viaja a España, con su amigo y compañero en las Cortes, Juan José Matheu y Herrera, Conde de Puñonrostro, diputado por la ciudad de Quito. Los dos

\footnotetext{
${ }^{23}$ R. Perez Pimentel: www.diccionariobiográficodeecuador.com. Página web del escritor e historiador ecuatoriano Rodolfo Pérez Pimentel. [Consultado 15- 3- 2011]

24 M. Chust (1999): «José Mejía Lequerica, un revolucionario en las Cortes hispanas». En Procesos: revista ecuatoriana de historia. $\mathrm{N}^{\circ} 14$. pp. 53-68.

${ }^{25}$ Es conocida la intervención de José Joaquín Olmedo en la proposición de abolición de las mitas. Diario de sesiones de Cortes, 4 de abril de 1812, p. 3007. Sobre el diputado por Guayaquil R. Roseco Jacome (1994): Olmedo. Político, patriota o desertor ... ¿ Quito. Editorial Eskeletra.

26 R. Perez Pimentel: www.diccionariobiográficodeecuador.com. Página web del escritor e historiador ecuatoriano Rodolfo Pérez Pimentel. [Consultado 15- 3- 2011]

${ }^{27}$ Ibídem
} 
futuros diputados gaditanos se encontraban en Madrid cuando estallaron los sucesos del 2 de mayo de 1808. Mexía, que había encontrado un empleo en el Hospital General de Madrid, defendió la capital madrileña en las barricadas que el pueblo, espontáneamente, levantaba contra las tropas francesas.

Cuando estaba a punto de capitular la villa en septiembre "disfrazado de carbonero" -como relataba a su mujer- abandonó Madrid rumbo a Sevilla, acompañado de su inseparable amigo el conde de Puñonrostro. Ambos realizaron el periplo que el acontecer de la contienda estaba marcando. Desde Madrid se trasladaron a Sevilla, para más tarde recalar en el último bastión del Estado español en la Península: Cádiz. Fue en esta ciudad en donde la convocatoria de la Junta Central y después de la Regencia les nombró diputados suplentes, Mejía por Santa Fe de Bogotá, y el conde de Puñonrostro por Quito. ${ }^{28}$

Así pues, comprobamos como Mexía Lequerica fue un hombre polifacético, ilustrado en el pleno sentido de la época, y con una envidiable formación y madurez intelectual, convirtiéndose a sus treinta y tres años en uno de los líderes de los liberales hispanos. ${ }^{29}$

Fue uno de los diputados teóricamente más sólido, más brillante y con una oratoria envidiable, pero sobre todo, es de destacar su coherencia personal, ideológica y política. Aparte de sus numerosas intervenciones, participó en una pluralidad de comisiones en las Cortes, entre las que destacamos las más importantes: la forma de publicar en América la instalación de las Cortes ${ }^{30}$, de sanidad pública ${ }^{31}$, de examen de empleos vacantes ${ }^{32}$, sobre el reglamento del poder ejecutivo $^{33}$, de la organización del gobierno, ${ }^{34}$ sobre el tribunal de Hacienda ${ }^{35}$, acerca de las infracciones a la Constitución ${ }^{36}$ y de la encargada del traslado a Madrid del gobierno ${ }^{37}$. Además de esta intensa actividad en las comisiones, en la

28 M. Chust (1999): «José Mejía Lequerica, un revolucionario en las Cortes hispanas». En Procesos: revista ecuatoriana de historia. № 14 . pp. 53-68.

${ }^{29}$ Ibídem

30 Diario de Sesiones de Cortes, 25 de septiembre de 1810. En adelante DSC

${ }^{31}$ DSC 20 de febrero de 1811

32 DSC, 6 de enero de 1811

33 DSC, 22 de octubre de 1811

${ }^{34}$ DSC, 2 de enero de 1812

35 DSC, 21 de abril de 1812

${ }^{36}$ DSC, 10 de enero de 1813

${ }^{37}$ DSC, 3 de octubre de 1813 
Cámara como orador, etc., le quedó tiempo aún para publicar el periódico $L a$ Abeja, uno de los más carismáticos dentro de la eclosión de la prensa liberal en Cádiz.

Por si todo ello fuera poco, Mexía participó, destacadamente, en una pluralidad de temas importantes, entre los que citamos la libertad de imprenta, la nulidad de los convenios hecho por los reyes en cautividad, el restablecimiento del crédito nacional, la abolición de la Inquisición, la extinción del tributo indígena y del repartimiento, la deposición de autoridades coloniales desafectas al régimen constitucional o la lucha por la igualdad de derechos y de representación de ambos hemisferios. ${ }^{38}$

A partir de este punto, sobre el resto de su vida, nos hacemos eco a través de los documentos otorgados antes y después de su fallecimiento: el poder para testar fechado el 25 de octubre de 1813, y el otorgamiento oficial de su testamento a manos de su primer albacea el 17 de noviembre del mismo año.

A grandes rasgos, el poder para testar de Mexía Lequerica presenta la estructura organizativa característica de este tipo de documentos. Una fórmula expositiva, donde tiene lugar la invocación a Dios Todopoderoso, seguido del nombre de testador y su lugar de procedencia del que se dice textualmente que era de el Reino de Quito, en el Perü ${ }^{39}$. También hallamos datos sobre su actividad profesional en el momento de otorgar el poder notarial, como diputado suplente por el Nuevo Reino de Granada, en el soberano Congreso Nacional de las Cortes Extraordinarias.

En lo que respecta al formulario de "encomendaciones" religiosas encontramos un predominio de las advocaciones marianas, de manera especial se pide la protección de la Virgen María, Reina de los Ángeles, a quien ruega interceda por la salvación de su alma, el perdón de sus pecados y el logro de la bienaventuranza del

38 M. Chust (1999): «José Mejía Lequerica, un revolucionario en las Cortes hispanas». En Procesos: revista ecuatoriana de historia. $\mathrm{N}^{\circ} 14$. pp. 53-68.

39 AHPC. Año de 1813. Sección de Protocolos Notariales. L. 1493.Es interesante el dato que nos aporta su poder notarial respecto a su origen geográfico, donde encontramos que el diputado era natural del Nuevo Reino de Granada, en el Perú. Es evidente la imprecisión geográfica que se tenía de la organización político-administrativa del continente americano en la época, ya que el Virreinato de Nueva Granada, y el Virreinato del Perú eran dos áreas bien diferenciadas territorialmente a partir de la primera mitad del siglo XVIII (1717/1739), pues con la creación del Virreinato de la Nueva Granada, con sede en Santa Fe, éste quedará formado por antiguos territorios que, como el Reino de Quito, habían formado parte del virreinato peruano. Por ello es obvio que, casi un siglo después, en la península se piense que Quito todavía seguía perteneciendo al primer virreinato que se creó en Suramérica, a saber, el del Perú. (Nota aclaratoria de la autora) 
más allá. Del mismo modo, le da gracias por permitirle disponer de tiempo para poder otorgar dicho testamento a pesar de la gravedad de su dolencia. Tras el obligado preámbulo religioso, comienza la parte dispositiva del documento, en donde se informa detalladamente acerca de la vida y muerte del testador, así como la elección del tipo de exequias. Estas, nos revelan la mentalidad ante la muerte en una época de creciente secularización.

El tipo de religiosidad, hallada en el poder, es propia del ritual funerario de la época: las exequias religiosas y la pompa fúnebre características del XVIII ${ }^{40}$, apenas aparecen, predominando en este documento una mayor sobriedad respecto al contexto funerario. ${ }^{41}$ Lequerica, pidió se le amortajara con el hábito que dispusieran sus albaceas, y se le enterrara en el cementerio de San José, extramuros de la ciudad ${ }^{42}$, con la forma y modo de funeral e inhumación que decidieran sus albaceas. Nos encontramos pues, ante una delegación en sus albaceas por parte del testador con respecto a sus exequias, lo que nos evidencia los cambios de ritual que ya estaban aconteciendo desde finales del siglo XVIII e inicios de la centuria decimonónica, cambios muy distintos al tradicional ritual barroco de la muerte. ${ }^{43}$

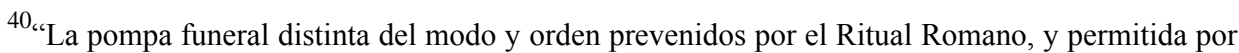
los cánones, y por las leyes, son más efecto o del honor de los vivos parientes o amigos del difunto, o de su vanidad, sobre lo qual, hay leyes, que si bien toleran cierto grado, prohíben otros. Nada sirve a los difuntos esta pompa, pero sí los sufragios, que también excitan la piedad de los vivos al mismo tiempo que les recuerda de los Novíssimos". Memorial de los curas párrocos de Cádiz. A. M. C. Sección Actas Capitulares. Cabildo de 24 de abril de 1802. fol. 208 v. M ${ }^{a}$ J. DE LA PASCUA (1990), señala en su obra Vivir la muerte..., que la Iglesia era consciente de este desarrollo de las pompas, fruto de la vanidad humana más que del deseo de albar a Dios, pero lo aceptaba como un mal menor al decir de los párrocos gaditanos. p. 139

${ }^{41}$ M J. DE la Pascua (1990): Vivir la muerte en el Cádiz del setecientos. Cádiz. Fundación Municipal de Cultura. p. 138: la autora señala que el final del siglo XVIII gaditano, nos ofrece la posibilidad de captar la descomposición del teatro barroco funerario de los siglos anteriores. También en S. GÓMEZ NAVARRO (1985): El sentido de la muerte y la religiosidad a través de la documentación notarial cordobesa (1790-1814). I. Análisis y estudio de los testamentos. Granada. p. 94, se señala la rapidez con la cláusula de los funerales va perdiendo contenido en el testamento de finales del XVIII y comienzos del XIX

${ }^{42}$ Recordemos la Real Cédula de 3 de Abril de 1787, donde se prohibían a partir de entonces los enterramientos intramuros. No obstante, hemos de destacar, que en Cádiz, dichas prohibiciones habían caído en saco roto, bien por la inercia del propio Ayuntamiento, bien por la falta de interés del cabildo eclesiástico o por la misma oposición de los fieles. A partir de 1800 , cuando comience a extenderse en Cádiz la epidemia de fiebre amarilla, comenzarían a cumplirse sin demora, ante la urgencia de la situación, las órdenes de la Real Cédula. Fue destinado como cementerio común el de la Parroquia de San José, extramuros de la ciudad, al que, dada su pequeñez, hubo que añadir un pedazo de terreno continuo. Ibídem,. p. 153

${ }^{43}$ Ibidem, p. 140.
} 
De todo ello, nos da fe en el presente poder notarial la austeridad de las pompas fúnebres, sin que ello merme la dignidad que conlleva el status social de la persona. La religiosidad pasa a un segundo plano, y a lo largo del texto, podemos entrever un cierto desapego a la vanidad terrenal y mundana, lo cual, está muy presente a lo largo del testamento de Mexía Lequerica.

En el apartado referido a los bienes materiales del diputado, observamos la escasez de los mismos, o al menos, su silenciamiento. Constatamos la ausencia de propiedades inmobiliarias, tierras, títulos financieros o nobiliarios, tan sólo se alude al sueldo que le asigna la Tesorería General por su actividad como diputado en las Cortes, sin especificar el montu del mismo, del cual, tiene que pagar el impuesto de 12 reales de vellón, según decidió el Congreso para los ejércitos nacionales, y asignar una pequeña parte para obras piadosas tras su muerte, lo que es habitual en las exequias fúnebres de la época. ${ }^{44}$ Como parte de sus bienes, también cuenta con una serie de libros de su propiedad, que deja en manos de Esteban Palacio, igualmente diputado a Cortes por Caracas, amigo del testador, y tío materno de Simón Bolívar.

Continúa el documento, refiriendo el nombre de sus albaceas. El primero de ellos, como venimos indicando, José de Peñaranda, capitán de navío de la Real Armada, comisario y apoderado del diputado, en quien parece depositar la mayor de las confianzas, encargado de llevar a cabo sus últimas voluntades. En segundo lugar, Juan Manuel Aréjula, uno de los principales médicos de la ciudad de Cádiz durante los años de la guerra, promotor de la campaña contra la epidemia de viruela acaecida en Cádiz en 1801, médico real de Carlos IV en 1804 y un año después, vicedirector del Colegio de Cirugía de Cádiz. ${ }^{45}$ A estos solicita, como parte del protocolo estipulado en este tipo de documentos, recauden y demanden "todo cuanto por cualquier legítimo título le pertenezca, haciendo una lista detallada de las personas que le deban cosa alguna, así como dispongan su testamento tal y como lo ha especificado". 46

Finalmente, señalaba que por ser soltero, circunstancia que no era del todo cierta, nombra como su única y universal heredera a Gertrudis Salanover y Benito,

\footnotetext{
44 Está estipulado en todos los testamentos, la entrega de una donación para obras piadosas, se habla de una cantidad acostumbrada en obras pías, pero no se especifica. No obstante, en los documentos del siglo XVIII, la cantidad habitual legada para obras pías eran cuatro reales de vellón, y a comienzos del siglo XIX, la cantidad aumenta a 5 reales de vellón.(Nota de la autora)

${ }^{45}$ R. Solís (2000): El Cádiz de las Cortes. La vida en la ciudad en los años de 1810 a 1813. (Prólogo de Gregorio Marañón). Madrid. Sílex. pp. 496- 499

${ }^{46}$ AHPC. Año de 1813. Sección de Protocolos Notariales. L. 1493.
} 
soltera y gaditana de origen ${ }^{47}$, en recompensa por los servicios particulares que le habia hecho" ${ }^{48}$ desde su llegada a Cádiz. Al parecer, con Gertrudis mantuvo un "cálido" romance durante su estancia en la ciudad, a pesar de estar casado en América con Manuela de Santa Cruz y Espejo 49 , a la que parece "olvidar" en sus últimas disposiciones; aunque su primer albacea, José de Peñaranda, convierte en heredera única y universal, contraviniendo con ello los deseos del finado.

Señalado el poder ${ }^{50}$, pasamos al testamento ${ }^{51}$ otorgado de forma oficial por el primero de sus albaceas, José de Peñaranda, quien expresa, que el diputado, recibió los santos sacramentos de la penitencia y la extremaunción, tras haber realizado momentos antes de su muerte, "muchos actos a amor a Dios y arrepentimiento de sus culpas”. Su cadáver, fue revestido en los términos, que según detalla el apoderado, "creyó más conveniente", y enterrado en el cementerio de San José Extramuros de la ciudad gaditana, con "la decencia correspondiente". 52 En la parroquia de San Antonio de la ciudad de Cádiz se llevaron a cabo unas austeras

47 AHPC. Año de 1813. Sección de Protocolos Notariales. L. 1493. Tal y como hemos comprobado en el Padrón de 1813, el estado civil de Gertrudis Salanover, no era soltera sino casada, con el peruano Joaquín Caldeiro. En cuanto a su origen geográfico, la fuente documental señala que no era natural de la ciudad de Cádiz, sino de Belmonte, en la provincia española de Cuenca.

${ }^{48}$ Ibidem

49 J. LONDOÑo (2009): Las mujeres de la Independencia. Campaña Nacional Eugenio Espejo por el libro y la lectura. Quito- Ecuador. Colección Bicentenaria. pp. 79- 82. Manuela Santa Cruz y Espejo, hermana menor de uno de los más importantes ilustrados y patriotas de la Audiencia de Quito, el Doctor Eugenio Espejo y Santa Cruz. Manuela, fue una mujer ilustrada de su época, cercana al ámbito de las ciencias naturales y la medicina, de claras convicciones patrióticas, alimentadas cotidianamente por la febril actividad de su hermano, y más tarde, por su esposo, José Mexía, discípulo de su hermano Eugenio en inquietudes filosóficas, políticas y científicas. Escribió para el primer periódico que tuvo la Audiencia de Quito, llamado Primicias de la Cultura, utilizando el seudónimo de Erophilia, y por ello, es considerada como la primera periodista de Quito. En 1798, a sus 40 años de edad, contrajo matrimonio con Lequerica, un joven de apenas 23 años.

${ }^{50}$ AHPC. Año de 1813. Sección de Protocolos Notariales. L. 1493. El testamento está fechado en 25 de octubre de 1813., dos días después, fallecería Lequerica.

${ }^{51}$ AHPC. Año de 1813. Sección de Protocolos Notariales. L. 1493.. Cádiz, a 17 de noviembre de 1813

52 R. PeReZ Pimentel: http://www.eruditos.net.diccionariobiograficoecuador.com: el 28 de octubre, un día después de su muerte, una procesión acompañó el cadáver del diputado al cementerio de la iglesia de San José Extramuros. El epitafio fue escrito por su amigo el diputado José Joaquín de Olmedo, y dice así: "A Dios glorificador. Aquí espera la resurrección de la carne, el polvo de D. José Mexía, Diputado a Cortes por Santa Fé de Bogotá. Poseyó todos los talentos. Amó y cultivó todas las ciencias: pero sobre todos, amó a su Patria y defendió los derechos del pueblo español con la firmeza de la virtud, con las armas del ingenio y de la elocuencia y con toda la libertad de un representante del pueblo. Nació en Quito, murió en Cádiz en octubre de 1813. sus paisanos y amigos escriben llorando estas letras a la posterioridad"'( Consultado 2- 7- 2010). 
exequias, reservándose la realización del funeral con toda su pompa para la Real Isla de León ${ }^{53}$, a petición del Soberano Congreso de las Cortes. Tras manifestar que todos los legados hechos por el testador fueron llevados a cabo, Peñaranda, nos aporta uno de los datos más reveladores del testamento de Lequerica: su verdadero estado civil, la evidencia de que éste no era un hombre soltero, sino que había contraído matrimonio en la ciudad de Quito el 29 de junio d 1796 con Manuela Santa Cruz y Espejo. Señala al respecto, que "por motivos" que desconoce, el diputado obvió dicho acontecimiento.

Por lo que hemos visto anteriormente de la biografía del diputado, al contraer matrimonio, tenía la edad de 21 años, mientras que la esposa contaba ya con 44, una diferencia de edad notable. También nos hacemos eco de la gran admiración y estima que Mexía de Lequerica profesaba al hermano de su esposa, el doctor Eugenio Espejo, su mentor, lo que puede traducirse que, por parte del discípulo, Lequerica, tras la muerte del maestro, había una necesidad de vincularse familiarmente a éste, a través del matrimonio con la hermana menor del mismo. Otro dato a tener en cuenta, es el de su casamiento en1796, apenas 9 años después, Lequerica partió hacia España, sin dejar, ni esperar descendencia, lo que posiblemente podría haberle llevado a buscar, aún siendo joven, una nueva compañera de vida.

El caso es que su albacea, a pesar de desconocer los motivos que llevaron al diputado a silenciar su matrimonio, creyó justo no incurrir en la equivocación sobre el estado civil de Lequerica, justificando así el honor y decoro que le corresponde a su verdadera y legítima esposa, a quien el apoderado, nombra como universal heredera, anulando por tanto, la cláusula que disponía como beneficiaria a Gertrudis Salanover y Benito, beneficiaria de 574 pesos fuertes, que era toda la fortuna dineraria que poseía el diputado ${ }^{54}$. Así pues, José de Peñaranda, tras haber

${ }^{53}$ La Isla de León es la actual ciudad de San Fernando, distante de Cádiz, unos 15 kms (Nota aclaratoria de la autora)

${ }^{54}$ El testamento otorgado por su primer albacea, José de Peñaranda, posterior al poder de 25 de Octubre, informa sobre los bienes económicos del diputado, que ascendían a 574 pesos fuertes. Para hacernos una idea de lo que representaba para la época dicha cantidad, señalaremos que, el sueldo medio de una sirvienta era entre 100 y 200 reales al mes, lo que suponía al año unos 120 pesos fuertes. Una de las disposiciones testamentarias analizadas en mi investigación nos muestra que una mujer heredó de un familiar, la cantidad de 30 pesos fuertes mensuales (600 reales de vellón), lo que suponía al año unos 360 pesos fuertes. Con dicha cantidad, la referida persona manifiesta que podía vivir desahogadamente. No obstante, hemos de tener en cuenta la situación de conflicto y de necesidad de estos años, así como el encarecimiento del precio de la comida y de la vida diaria en general. En otra de las disposiciones, hallamos que la manutención de una niña pequeña de cinco años, suponía al mes la cantidad de 8 pesos fuertes. Igualmente otro documento (partición de bienes) 
realizado por correo todas las gestiones pertinentes con la legítima esposa del finado, Manuela Santa Cruz, quien desde Quito, le envió los documentos necesarios que ratificaban la legitimidad del matrimonio, nombrara a ésta heredera única y universal del exiguo capital metálico y del diputado. De esta forma concluye el testamento, revelando el verdadero estado civil de Mexía Lequerica. ${ }^{55}$

\section{BIBLIOGRAFÍA, FUENTES DOCUMENTALES Y REFERENCIAS WEB.}

\section{Bibliografía}

Armillas, J. A., SuÁrez Fernández, L., y Corona Baratech, C. (1984): Historia General de España y América: La España de las reformas hasta el final del reinado de Carlos IV. Madrid: Ediciones Rialp S. A.

Chust, M. (II Semestre. 1999): «José Mejía Lequerica, un revolucionario en las Cortes hispanas». En Procesos: revista ecuatoriana de historia. $\mathrm{N}^{\circ} 14$. pp. 53-68

Chust, M. (1999): La cuestión nacional americana en las Cortes de Cádiz (1810-1814). Valencia. Biblioteca Historia Social.

DE LA PASCUA, Ma J. (1990): Vivir la muerte en el Cádiz del setecientos. Cádiz. Fundación Municipal de Cultura. pp. 138-153

DEL CERRo BoHóRQuez, M ${ }^{\mathrm{a}}$ P. (2005): Mujer, herencia y patrimonio en la sociedad rural gaditana del Antiguo Régimen. Alcalá de los Gazules, Chiclana de la Frontera y Medina Sidonia. (1670- 1750). Cádiz. Servicio de Publicaciones de la Universidad de Cádiz.

de la misma época nos revela el valor material, estipulado en unos 800 pesos fuertes de todo un ajuar doméstico de las siguientes características: 24 cubiertos de plata compuestos de cuchara, tenedor y cuchillo de cabo negro; tres docenas de platos llanos; una cuchara sopera; una salbilla de dicho metal; seis candeleros de plata, y 12 cucharillas con concha y cabo de plata. Por su parte, un ajuar completo de ropa de casa, menaje y muebles, podía ascender a 500 pesos fuertes; y el precio de dos coches de caballos, uno de estilo inglés, y otro de estilo milanés, se calculaba en unos 700 pesos fuertes. En G. ZarZa Rondón: Cádiz, Puerto y Puerta de América, la presencia de hispanoamericanos en la ciudad entre 1765 y 1840. (Tesis Doctoral. En prensa)

También podemos comparar dicha cantidad con los salarios habituales del funcionariado estatal en la Isla de Cuba para la primera mitad del siglo XIX. Por ejemplo, un escribiente, contaba con un sueldo anual de 360 pesos; un administrador de rentas, tenía un salario que oscilaba entre los 800 y los 1.000 pesos. Dentro del estamento militar, un subteniente y alférez, podía ganar anualmente 564 pesos fuertes; un teniente de navío, 660pesos; un teniente de marina, 360 pesos; y un contramaestre $2^{\circ}$, contaba con un sueldo de 228 pesos al año. En M ${ }^{a}$ Dolores PéreZ Murillo (1988): Aspectos demográficos y sociales de la Isla de Cuba en la primera mitad del siglo XIX. Cádiz. Servició de Publicaciones de la Universidad de Cádiz. pp. 182- 189.

55 AHPC. Año de 1813. Sección de Protocolos Notariales. L. 1493. Cádiz, a 17 de noviembre de 1813. pp. 156- 169. Los testigos y el escribano, los mismos que habían firmado el poder del diputado de 25 de octubre. 
EIRAS RoEl, A.(1980): «La documentación de Protocolos Notariales en la reciente historiografía modernista», en Estudis Historics i Documents dels Arxius de Portocols, Barcelona, ${ }^{\circ}$ VIII. pp. 7-77

Gómez NAVARro S. (1985): El sentido de la muerte y la religiosidad a través de la documentación notarial cordobesa (1790-1814). Análisis y estudio de los testamentos. Granada, p. 94

Londoño, J. (2009): Las mujeres de la Independencia. Campaña Nacional Eugenio Espejo por el libro y la lectura. Quito- Ecuador. Colección Bicentenaria. Quito- Ecuador. pp. 79-82

Paniagua PÉRez, J. (2009): Morir en Cádiz (1650-1859). La vida y la muerte de las gentes de los obispados de Astorga y León en Cádiz, así como de Oviedo en la provincia de León. León. Editorial Lobo Sapiens.

RIEU- Millan, Ma L. (1990): Los diputados americanos en las Cortes de Cádiz.Madrid. Biblioteca de Historia de América. CSIC.

RoDRÍGUEZ DE GRACIA, H. (1991):«Análisis de algunos inventarios y testamentos toledanos», en Toletvm. p.139

Ruiz RiverA, J. (1988): El Consulado de Cádiz. Matrículas de comerciantes. 1730- 1823. San Fernando. Diputación Provincial de Cádiz. p. 176

SANCHIZ, J., y Conde DíAz Rubín, J. I. (2005): «La familia Monterde y Antillón en Nueva España. Reconstrucción genealógica (Primera parte)». En Estudios de historia novohispana, pp 93-164.

Solís, R. (2000): El Cádiz de las Cortes. La vida en la ciudad en los años de 1810 a 1313. Madrid. Sílex Ediciones. p. 270 y pp. 469- 499

Zarza Rondón, G.: Cádiz, Puerto y Puerta de América: presencia de hispanoamericanos en la ciudad entre 1740 y 1840 . (En prensa).

\section{Fuentes Documentales}

\section{$\checkmark$ - ARCHIVo HistóRICO PROVINCIAL DE CÁdIZ}

1. Sección de Protocolos Notariales. Libro 1493. Año de 1813. pp. 92- 98. Poder para testar de 25 de octubre de 1813 de José Mexía Lequerica a José de Peñaranda y Juan Manuel Aréjula.

2. Sección Protocolos Notariales. Libro 1.493. Año de 1813. pp. 156- 169. Testamento de 17 de noviembre de 1813 otorgado por su primer albacea José de Peñaranda

$\checkmark$ - ARChivo Histórico Municipal de CÁdiz

1. Año de 1810. Sección de Padrones. $N^{\circ}$ de Orden L. (Libro) 9.401 y L. 9.476;

2. Año de 1811, Sección de Padrones. No de Orden L.1.044 al L. 1.054 (10 tomos);

3. Año de 1812. Sección de Padrones. $N^{\circ}$ de Orden L.1.031 al L. 1.043 (13 tomos);

4. Año de 1813. Sección de Padrones. No de orden L. 1.055 al L. 1.060 (6 tomos)

$\checkmark$ - Archivo Parroquial de la IGLESia de SAN ANTONio de CADIZ

1. Libro de defunciones $\mathrm{N}^{\circ} 4$, folio 47, $\mathrm{n}^{\circ} 461$. Extracto de acta de defunción de Don José Mexía y Lequerica. 


\section{Referencias Web}

Perez PIMENTEL, R.: http://www.diccionariobiográficodeecuador.com. Página web del escritor e historiador ecuatoriano Rodolfo Pérez Pimentel. [Consultado 15- 3- 2011]

PEREZ PIMENTEL, R.: http://www.eruditos.net.diccionariobiograficoecuador.com [Consultado 2- 7 2010]

WeB DE LA BiBlioteCA NACIONAL: http://bdh.bne.es/bnesearch/detalle/91165: Cádiz. Planos de Población 18. [Material Cartográfico] [Consultado 19- 10 2011]

\section{APÉNDICE DOCUMENTAL}

\section{Poder para testar del señor D. Josef Mexía Lequerica a D. Josef Peñaranda y otros. $^{56}$}

[Nota primera al margen izquierdo de la primera página]

El día de su fecha di copia de este documento a el Sr. Otorgante descrito en papel de sello de a cuarenta maravedíes. Doy fe (Antonio Govirand y Martínez)

[Nota segunda al margen izquierdo de la primera página]

En Cádiz a treinta y uno de octubre de mil ochocientos y trece Yo el escribano di copia de este poder a $\mathrm{D}^{\mathrm{a}}$ Gertrudis Salanover y Benito, heredera del testador por haberme manifestado el fallecimiento a las ocho de la noche del día veinte y siete del corriente. Escrito en papel de sello de cuarenta maravedíes. Doy fe--- Govirand.

En el nombre de Dios Nuestro Señor todo poderoso, y su Divina gracia Amen: Yo D. Josef Mexía, Diputado que he sido del Soberano Congreso Nacional en las Cortes Extraordinarias y actual suplente de las ordinarias, natural que soy del Nuevo Reino de Granada en el Perú, hijo lexítimo de D. Josef Mexía y Da Joaquina Lequerica, ya difuntos, hallándome gravemente enfermo en cama, aunque por la Divina Misericordia en mi libre juicio, memoria y entendimiento natural que Dios Nuestro Señor ha sido servido concederme, creyendo como firme y verdaderamente creo en el Soberano Misterio de la Santísima Trinidad, Padre Hijo y Espíritu Santo, tres personas distintas y un solo Dios verdadero: En el de la Encarnación del Verbo Eterno, en las purísimas entrañas de la Virgen María Nuestra Señora que concibió sin mancha de pecado original en el primer instante de su anunciación, y en el Santísimo Sacramento del Altar y finalmente en todos los demás Artículos y Misterios que tiene cree y confiesa la Madre Iglesia Católica, Apostólica y Romana bajo cuya fe y creencia he vivido y con el divino auxilio

\footnotetext{
${ }^{56}$ Archivo Histórico Provincial de Cádiz. Sección Protocolos Notariales. Poder para testar del 25 de octubre de 1813. signatura 1.493, pp. 92- 98.
} 
protexto (sic.) vivir como católico y fiel cristiano. Conociendo la certeza de la muerte, lo dudoso de su hora y deseando para cuando llegue la de mi fallecimiento tener en el modo posible dispuestas y ordenadas las cosas tocantes al descargo de mi conciencia y bienestar de mi Alma para el logro de la quietud del Espíritu y de la Bienaventuranza, invoco como mi especial protectora y abogada a la Serenísima Reina de los Ángeles María Santísima Nuestra Señora para que interceda con su preciosísimo hijo, perdone mis pecados y ponga mi Alma en carrera de Salvación: mediante lo cual, y no pudiendo como por ahora no me es posible disponer mi testamento con la extensión que se requiere a causa de la gravedad de los accidentes de que adolezco y respecto a que los asuntos de mi cargo y conciencia los tengo conferidos y convenidos con los individuos que voy a nombrar: otorgo que doy y concedo mi poder cumplido tan bastante como por derecho se requiere y es necesario, en primer lugar â D. Josef de Peñaranda, por su falta, ausencia û otro impedimento legítimo, en segundo lugar â D. Juan Manuel Aréjula, ambos vecinos de esta dicha ciudad para que en mi nombre y representación de mi persona después de mi fallecimiento hagan y otorguen mi testamento y última voluntad arreglándose para ello a lo que les tengo comunicado en las cláusulas siguientes:

$1^{\text {a }}$ - Para que verificada mi muerte los citados mis comisarios dispongan que mi cadáver sea revestido y amortajado con el hábito o en el modo que consideren por conveniente y sea sepultado en el cementerio de la Iglesia de San Josef extramuros de esta ciudad. A decisión y arbitrio lo dejo todo ello así como el número de misas que por mi alma haya de celebrarse pagándose de mis bienes el costo que todo ello tenga y dándose a las mandas pías forzosas la limosna que es costumbre incluyéndose la asignación que tiene hecha las Cortes para los Ejércitos Nacionales.

$2^{\mathrm{a}}$ - Para que declaren como yo lo hago que los bienes que al presente me hallo se deducen solamente de los sueldos que se me están entregando por la Tesorería General mas los libros que tengo en la Villa de Madrid a cargo de D. Juan Peñuela, los que existen en propiedad de Esteban Palacio, los que conserva en su propia casa y los que tiene prestados a diferentes amigos, todos los cuales deberán recoger los referidos mis comisarios como así mismo los reales que están en poder de mi escribiente.

$3^{\mathrm{a}}$ - Prevengo que en poder de D. Josef de Peñaranda se hayan ciertos papeles reservados los cuales es mi voluntad conserve en sí, y por lo tocante a los demás dispondrá de ellos según lo estime conveniente y le diste (sic) su conciencia y conocimiento. 
$4^{\mathrm{a}}$ - Para que los dichos papeles dejados a D. Josef de Peñaranda y a D. Juan Manuel Aréjula por el orden que quedan señalados se nombren como yo desde luego los nombro por mis albaceas testamentarios, cumplidores y ejecutores de esta mi última voluntad y les doy poder cumplido de albaceazgo en forma para que después de mi fallecimiento entren en mis bienes y tomen los que gusten, y en alguna moneda publica los vendan, con cuyo valor suplan y paguen lo que dejo dispuesto en este poder, y contuviere el testamento escrito en virtud de otorgarse dentro ô fuera del término que disponen las Leyes de estos reynos (sic) que les prorrogo todo lo demás que necesitaren facultándoles competentemente para que hagan, demanden y recauden todo cuanto por cualquier lexítimo (sic) título me pertenezca y pueda corresponder, y tomen cuentas â todas las personas que me las deban dar, haziéndoles (sic) cargo y dando y otorgando recivos (sic), cartas de pago, finiquitos y los demás instrumentos que sean necesarios, así como entregar y conferir con respeto a las Leyes y Juicio de los derechos de mi testamentaria en los Tribunales Superiores e inferiores que convenga, promoviendo cuantos recursos sean necesarios con libre, franca y general administración, con la facultad de enjuiciar, jurar, sobstener (sic), revocar y nombrar.

$5^{\mathrm{a}}$ - Para que los dichos mis comisarios y apoderados puedan hazer (sic) y hayar (sic) cualesquiera (sic) legados o mandas que acaso les dejase comunicado es mi voluntad que a lo que dispusieren, legaren o encomendaren se cumpla enteramente, dándosele la propia fe y validación que por mi parte aquí expreso y dejo aclarado

$6^{\text {a }}$ - Para que en el remanente que después de cumplido y pagado lo que dejo dispuesto en este poder y contuviese el Testamento que en su virtud se solemnizare, quedare de todos mis bienes, créditos, derechos, acciones y futuras donaciones que en cualesquiera(sic) manera me pertenezcan puedan tocar y pertenecer mediante a ser de estado soltero y no tener herederos forzosos descendientes ni ascendientes que según derecho me puedan y deban heredar, instituyan y nombren como yo desde luego instituyo y nombro por mi única y universal heredera a $\mathrm{D}^{\mathrm{a}}$ Gertrudis Salanover y Benito, de estado soltera y residente en esta ciudad de Cádiz en recompensa de los particulares servicios que me ha hecho y he debido a la misma y porque es mi voluntad.

$7^{\mathrm{a}}$ - Y para que con lo que he dicho se reboquen ( sic) dichos mis comisarios y apoderados como yo desde luego reboco ( sic) cualquier otro documento por escrito de palabra o en otra qualquiera (sic) forma para que no valgan y hayan fe en juicio ni fuera de él salvo este poder para textar (sic) y el testamento que en su virtud se solemnizare, que uno y otro guarden, cumplan y ejecuten por última voluntad. 
Dio testimonio en la ciudad de Cádiz a veinte y cinco dias del mes de Octubre de mil ochocientos y trece el Señor otorgante a quie3n yo, el Infrascripto doy fe conosco (sic) lo heredado y en mi registro conociendo por testigos D. Josef Fernández de Castro, D. Manuel de Arellano y D. Miguel de Bustinaga, vecinos de Cádiz.

Jose Mexía Lequerica

Antonio Govirand Martinez

\section{Testamento de D. Josef Mexía y Lequerica hecho en virtud de poder por D. Josef de Peñaranda su primer comisario ${ }^{57}$}

En el nombre de Dios Nuestro Señor Todo poderoso y con su Divina gracia Amen: Yo Dn. Josef Peñaranda, Teniente de navío de la Armada Nacional, residente en esta ciudad de Cádiz albacea testamentario en primer lugar del Señor Dn. Josef Mexía Lequerica, Diputado que fue del Soberano Congreso en las Cortes Extraordinarias del Reyno (sic) y posteriormente suplente en la actuales ordinarias por el Reyno (sic) de Granada en el Perú: su apoderado y comisario con amplitud y facultades en el poder para testar que otorgó bajo la protección de Nuestra Santa Fe Cathólica (sic) el día veinte y cinco de Octubre del presente año, por el que dejó su funeral, misas y entierro a disposición de los albaceas que nombró, ordenó que por nosotros se hiziese ( sic) con arreglo a sus comunicados las manifestaciones que tubiésemos (sic) por conveniente: instituyó heredera y rebocó (sic) otras anteriores disposiciones, cuyo poder para testar pido â dicho escribano Infrascripto lo inserté y precopié (sic) tras haber fallecido bajo su contexto como lo hago, y lo continuo como Sigue:

[A continuación encontramos una copia del poder para testar anteriormente expuesto. Tras él, continúa el testamento otorgado por su primer comisario]

Nota. Día de su fecha di copia de este poder a el Señor otorgante escrita en papel del sello segundo y de a quarenta maravedíes (sic), doy fe. Govirand

Nota. En Cádiz a treinta y uno de octubre de mil ochocientos y trece, yo el escribano di copia de este poder a $\mathrm{D}^{\mathrm{a}}$ Gertrudis Salanover y Benito, heredera del testador por haberme manifestado falleció a las ocho de la noche del día veinte y siete del corriente, escrita en pape de sello segundo y el intermedio de a quarenta maravedíes (sic), doy fe. Govirand

${ }^{57}$ Archivo Histórico Provincial de Cádiz. Sección Protocolos Notariales. Testamento de 17 de Noviembre de 1813. signatura 1.493, pp. 156- 169. 
Prosigue: El poder para textar (sic) está conforme a su original que queda en mi rexistro (sic) de que doy fe y a que me remito.

Usando de las facultades que por él me han sido concedidas otorgo: Que hago y ordeno el testamento y última voluntad del expresado Señor Dn Josef Mexía y Lequerica no solo con arreglo a las cláusulas que contiene el mismo poder, sino también con las alteraciones y demás objetos que recerbadamente (sic) me comunico antes de su fallecimiento en la forma siguiente:

$1^{\text {a }}$ - Lo primero declaro que el referido Señor Dn Josef Mexía, habiendo recivido (sic) los Santos Sacramentos de la penitencia y Extremaunción, y haziendo (sic) muchos actos de amor de Dios, y arrepentimiento de sus culpas, falleció en esta dicha ciudad el día y la hora que demuestran la nota que queda incerta (sic), y su cadáver rebestido ( $\mathrm{sic}$ ) en los términos que estimé convenientes, fue enterrado y sepultado en el Sementerio (sic) General de la Yglesia (sic) de el Señor San Josef Extramuros de esta Plaza, con la desensia (sic) correspondiente no habiéndosele por mi hecho, como primer albacea funeral alguno, porque se le hizo funeral en la villa inmediata de la Real Isla de León por el Soberano Congreso Nacional de que era individuo suplente por dicho nuevo Reyno (sic) de Granada en el Perú, y se ha celebrado en sufragio de su alma el número de misas que he estimado conveniente por los sacerdotes, y por la limosna que resulta de los respectivos recivos (sic) que existen en mi poder, habiéndose dado a las mandas pías forzosas la limosna acostumbrada, y la de los doze ( sic) reales que en calidad de tal se ha dispuesto por las Cortes para los fines urgentes del Estado, con lo que los excluyo, el difunto Dn Josef Mexía los excluyó del Derecho que pudieran pretender a sobre sus bienes.

$2^{\mathrm{a}}$ - Con arreglo a lo que el testador referido por la cláusula segunda de su dicho poder para textar (sic) declaro, que los únicos bienes que poseía el señor difunto consistían en el importe de los sueldos que debía haber por razón de su alto ministerio y que se le estaban adeudando por la Tesorería General del Reyno; (sic) una porción de libros que expresó con equivocación existían en poder de Dn Juan Peñuelas, vecino de la Vila de Madrid, pues estos realmente paran en el de la viuda de Dn Manuel Alonso, librero que fue en ella: los que de su propiedad existen en poder de Dn Esteban Palacios, otros que tenía en la propia casa de su habitación, y diferentes que había prestado a distintos sujetos, sus amigos, todos los quales (sic) procuraré recoger formalizando con éxito Ymbertario (sic) de ellos para proceder a su enajenación, venta o en los términos que sea más conducente a la intención del difunto.

$3^{\text {a }}$ - Asimismo declaro que por perteneciente al nominado Dn Josef Mexía se hallaban en poder de su Escriviente (sic) Dn Diego Gómez quinientos setenta y 
quatro (sic) pesos fuertes que he recogido para darles el giro $\mathrm{y}$ destino correspondiente

$4^{\text {a }}$ - Según lo que expuso el testador por la cláusula tercera de dicho poder para textar (sic), manifestó ser cierto y constante que existen en mi poder varios papeles recerbados (sic) que según su orden debo concervar (sic) en mi poder y de otros que no son de esta clase, dispondré a mi arbitrio y prudencia como lo estime oportuno según la mente y disposición del testador.

$5^{\mathrm{a}}$ - Igualmente declaro que aunque el nominado Dn Josef Mexia y Lequerica manifestó en dicho poder para textar ( sic) ser de estado soltero, esto fue por ciertos motibos recervados (sic), y que no quiso declarar por si no se verificaba su fallecimiento, pero expresa y determinadamente me comunico y me consta por carta de correspondencia que he visto y reconocido, que era de estado casado con Manuela Santa Cruz y Espejo, natural de la ciudad de Quito en la que había celebrado su matrimonio lexítimo según orden de Nuestra Santa Madre Yglesia (sic) y disposición del Santo Concilio de Trento el año pasado de mil setecientos noventa y seis siendo Padrinos Dn Juan de Dios Morales y Da Josefa Tinajero: lo que aquí manifiesto para que quede deshecha aquella equivocación o recerba ( sic), y que la citada su esposa quede viuda del mismo con el honor y decoro que corresponde a su clase, y con la acción competente para repetir de su testamentaria los intereses, derechos y acciones que deba haber como su lexítima (sic) consorte.

$6^{\mathrm{a}}$ - Y en fuerza de la voluntad del textador (sic) y expreso comunicado, hago legado del tercio y remanente del quinto de todos los bienes, derechos y acciones que por qualquier lexítimo (sic) titulo pertenezcan y puedan pertenezer (sic), así en esta Península como en Quito y su Provincia al nominado Dn Josef Mexía y Lequerica a favor de la enunciada su consorte $D^{a}$ Manuela Santa Cruz y Espejo para que todo lo que así fuere y se liquidare por su testamentaria lo haye, llebe (sic) y herede en propiedad y usufructo.

$7^{\mathrm{a}}$ - Y a consecuencia de lo que dispuso el textador ( sic) por la cláusula quarta (sic) del dicho poder para textar (sic), me nombro y elijo en primer lugar y en segundo â Dn Juan Manuel de Aréjula por albaceas testamentarios, tenedores de bienes cumplidores y ejecutores de su ultima voluntad y me doy y le doy poder cumplido de Aalbaceazgo en forma para vender qualesquiera (sic) de los bienes del textador (sic), para cumplir quanto (sic) dejó dispuesto en el citado poder y que contiene este testamento en su virtud otorgado, concediéndome y concediéndole las amplias facultades que comprehende (sic) la misma cláusula relativa a cobrar, recaudar, pedir y tomar cuentas, transigir, comprometer y poner en juicio de defensa todos los Derechos de su Testamentaria con libre franca y general 
administración, relebación (sic) y facultad de poder este encargo en las personas y las veces que nos pareciere por el orden explicado, rebocar (sic), subtitular y nombrar otros bajo la misma relevación (sic).

$8^{\mathrm{a}}$ - Y en fuerza de lo que dispuso el textador (sic) por la cláusula sexta del preincerto (sic) poder para textar ( $s i c$ ), en el remanente que después de cumplido y pagado lo que en él dejo ordenado y comprehende (sic) este testamento, instituyo y nombro en su representación como heredera única universal del referido Dn Josef Mexía a $D^{a}$ Gertrudis Salanover y Benito, de estado soltera y residente en esta ciudad de Cádiz para que todo lo que así fuere lo haye, llebe (sic) y herede la referida en propiedad y usufructo con la bendición de Dios Nuestro Señor.

$9^{\mathrm{a}}$ - Y con lo que he dicho reboco ( sic) como el textador (sic) lo hizo por la cláusula séptima del precopiado poder para textar (sic), anulo, doy por ningunos, rotos y chancelados (sic) y de ningún valor ni efecto todos y qualesquiera (sic) testamentos, codicilos, poderes para textar ( sic) y otras ultimas disposiciones que antes de ahora haya hecho el referido por escrito de palabra o en otra cualesquiera (sic) forma para que no valgan ni hagan fe en juicio ni fuera de él salvo el expresado poder y este testamento en su virtud solemnizado, que uno y otro quiero se conserve, guarde, cumpla y execute ( sic) por su ultima determinada voluntad en aquel día: En cuyo testimonio así lo otorgo en la ciudad de Cádiz a dies (sic) y siete días del mes de Noviembre de mis ochocientos trece: y el otorgante a quien Yo el dicho escribano publico doy fe conosco (sic) lo firma en mi rexistro siendo testigos Dn Josef Lozano, Dn Josef de Moya y Dn Manuel de Arellano, vecinos de Cádiz.

José de Peñaranda

Ante mí: Antonio Govirand y Martinez 